\title{
VALUE CREATION PERCEPTIONS OF MANAGEMENT ACCOUNTANTS IN SOUTH AFRICA
}

\section{Danie Schutte, Jacques Hugo and Erica Derbyshire}

\author{
School of Accounting Sciences, North-West University
}

Cite this article:

Schutte D., Hugo J., Derbyshire E. (2021), Value Creation Perceptions of Management Accountants in South Africa. African Journal of Accounting and Financial Research 4(3), 120-138. DOI: 10.52589/AJAFR-

IIYTW7VP.

\section{Manuscript History}

Received: 11 Oct 2021

Accepted: 1 Nov 2021

Published: 14 Nov 2021

Copyright $\odot 2020$ The Author(s). This is an Open Access article distributed under the terms of Creative Commons AttributionNonCommercial-NoDerivatives 4.0 International (CC BY-NC-ND 4.0 ), which permits anyone to share, use, reproduce and redistribute in any medium, provided the original author and source are credited.

\begin{abstract}
The Coalition for Inclusive Capitalism launched the Embankment Project for Inclusive Capitalism (EPIC) to tackle the challenge of communicating how value is created for the stakeholders of a company. However, discord on how stakeholder value should be measured exists. Management accountants can successfully measure the value of money in their cost control function, but it remains a challenge on how they perceive the adding or creating of value in their respective roles and if their own perceived performance. The aim of this study was to obtain an understanding study of how management accountants view and navigate through this concept of value creation in general and in their organisation, how and why they engage in value-creating activities for their organisations and its stakeholders. A qualitative approach was adopted to conduct the study and the data collection technique constituted a literature review and questionnaires distributed to 30 participants. The majority of the participants believe that they are creating value for their organisations and positioned their perceived value creation into the economic value category. Some participants believe that the value they create within their organisation cannot be measured. Overall, it is recommended that possible development of tools, models or frameworks to assist management accountants in the measuring or capturing of value should be explored that is of a more subjective nature, so that it would be easier to implement and drive value creation practices in the workplace.
\end{abstract}

KEYWORDS: Management Accountant, Value Creation, Stakeholders, Performance, Measurement 


\section{INTRODUCTION}

The public's trust in institutions and business corporations all around the world is at an all-time low, with only the trust in governments being lower (Kammel, 2019). More and more businesses are turning to a concept known as "inclusive capitalism", moving away from "financial capitalism", in an effort to win back the trust of the public. Inclusive capitalism is the idea that a company should not just generate profits, but also create value that reaches stakeholders locally and on a global scale (Carney, 2014). When pondering on the principles of inclusive capitalism, one cannot help but wonder what it means to create value, especially when it comes to balancing the different perceptions of value for the different stakeholders to whom the business is accountable.

One of the most substantial changes that have occurred in the global business landscape has been the way value is viewed within the business context (Porter et al., 2012). Measuring value creation however remains a key challenge, since value is perceived differently by different businesses and hence measured differently (Hansell, 2012). Value creation in business, along with the perceptions of what different stakeholders consider to be valuable have been a contentious issue for as long as the world of business has been in existence (Hansell, 2012). Tension between shareholders and management of companies remains a pressing theme when it comes to issues of creating long-term shareholder value and other management objectives (Lockhart \& Taitoko, 2005). Purpose-driven, sustainable strategies are beneficial to shareholders and the communication of these strategies enables the shareholders to understand the prioritisation of business activities (Laszlo, 2008).

When it comes to value creation for businesses, no one person or group in a company can create value on their own. It is the result of collaboration throughout the entire organisation, but the finance function plays an integral role in providing the framework within which value is created (Hofmann, 2003). Freudenreich et al. (2019) believes that since the business model dictates the way in which action planning, strategy formulation, risk management and governance are utilised to put the process that is followed for value creation into motion, management accountants are best suited for this role. Finance can no longer be viewed as an overhead only, but has a key role in enabling growth and realising strategy, and organisations should structure the role of the finance function to support this view in their process of value creation, so that the finance function could maximise its contribution to the goals of the organisation (CGMA, 2012). However, even though the finance function potentially might have a more active role to play in value creation, it is often convenient to revert back to traditional performance indicators. There exists a pressing issue, when it comes to the administrative problem, of companies not being able to create reliable or accurate performance management that is based on the strategic planning of where the entity is heading. It poses a serious difficulty to determine the appropriate level of achievement for each role-player to be able to "create value" within the framework of available objectives and expectations (Lyibildiren, 2017). Using financial information as the basis for performance measurement provides accurate and objective results. However, the calls for more inclusive capitalism demand a type of value that is not always quantifiable. This context wherein businesses are functioning places the management accountant in a position where financial performance methods are inadequate at various points. 


\section{LITERATURE REVIEW}

\section{Value, and the concept of value within an organisational context}

The concept of value is a very equivocal subject, which has been theorised about for the past two and a half millennia. Pitelis (2009) proposed a definition of value at the level of the "individual agent". This proposed definition is that "[v]alue is perceived worthiness of a subject matter to a socio-economic agent that is exposed to and/or can make use of the subject matter in question". Pitelis (2009) further explains that the benefit of the proposed definition is that it makes provision for the concept of value to not have to be dependent on the notion of "willingness to pay", which implies that a market price or even a market exists. It, therefore, makes provision for the possibility of inherent value.

Organisational value is understood through the activities, processes, services and products developed by the organisation, which are regarded as valuable by prospective recipients, such as customers, distributors or competitors (Zwikael \& Smyrk, 2011). Organisational value, according to Pitelis (2009), can either be surmised or recognised. Surmised value is what an organisation expects it can achieve by pursuing an activity, such as a new invention or engaging in a trade. Recognised value is achieved through a trade in a market; the value that is created is subsequently recognised as value captured.

With the literature on value creation in an organisational context still relatively limited, this proposed definition of value by Pitelis (2009) was adopted for this study to understand the perception of management accountants on value creation through the use of the stakeholder theory. To ultimately understand what a stakeholder perceives to be valuable, it needs to be considered that the nature of value is subjective and multi-faceted and cannot be defined on its own, and is void of context or people to ascribe that value. Bowman and Ambrosini (2007) explain that the stakeholders' level of relationship with the organisation informs the perception of what that stakeholder deems to be valuable at that time.

Hart and Milstein (2003) defined value creation as a process or activity that concurrently enhances a positive impact and reduces the negative impact of the organisation while creating economic value for its shareholders. This definition is sufficient in explaining value for stakeholders with a financial incentive, but the stakeholders with a non-financial incentive do not necessarily define their value as being only economic in nature, so this definition also fails to capture value for all the stakeholders of the organisation.

The stakeholder theory proposed by Freeman (2010) provides the best explanation on how an organisation's ability to create sustainable wealth in the long term can be effectively determined by looking at the organisation's key relationships. This theory examines the value creation processes and activities of an organisation, which both informs and is informed through the contributions of those key relationships of the organisation. Therefore, stakeholders are those groups who are affected by or affects an organisation, and who contribute to the value creation of the organisation (Garriga, 2014). The stakeholder theory is brought to the forefront on issues such as the prioritisation of different corporate objectives when weighing up the interests of the different stakeholders who have a vested interest with the organisation. This is the focal point of the global corporate governance debate over whether companies should maximise shareholder value or act in the interests of their stakeholders (Jensen, 2010). It delves deep into the emotional commitments of most individuals to the 
organisation and helps to gain a better understanding of the relationships within and relating to an organisation, and provides insight into the effects that performance has on these relationships (Jensen, 2010).

\section{Levels of value creation and value creation approaches}

To create sustainable value for the organisation, value maximisation cannot be the sole objective. If value maximisation is used as the corporate scorecard, it needs to be complemented by the strategy and the vision of the company that will unite the participants in the company in creating a sustainable competitive advantage. It is, however, imperative that within this framework, the different interests be weighed.

Value creation can be observed on three levels, as illustrated below.

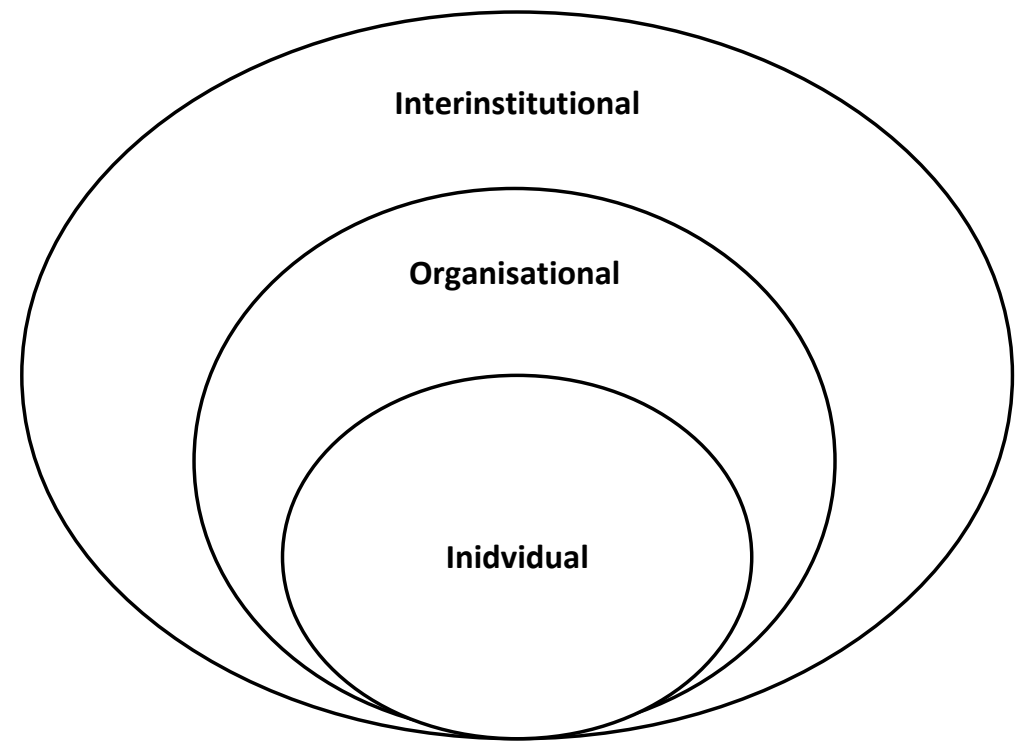

Figure 1 - Three levels of value creation

Source: Lepak et al., 2007

On an individual level, individuals create value by behaving innovatively within their role to make the output or experience more novel and more suitable for the organisation, or for any end-user who has an interest in the output or experience (Lepak et al., 2007). There are four types of individual value an individual can add to an organisation. One, economic value, which is simply created when the price that consumers pay for products and services is higher than the cost of creating them. It has a measurable monetary value (Argandoña, 2011). Second, philosophical value, that is defined as ethical behaviour towards the social spheres the organisation operates in and assuming a moral responsibility to the protection of the environment (Schilizzi, 2000). Third, subjective value, the idea that every entity (individual or organisational) has their own desires for artefacts or actions (Robertson \& Tang, 1995). Economists use this term to interpret market behaviour and it is the notion that value is not 
inherent in things. This value depends solely on the perception, preference and experience of the entity who imputes the value. Fourth, objective value, that is also known as "intrinsic value" (Audi, 2003). Individuals ascribe objective value through the process that the artefact is created to impute value into the end result (Audi, 2003).

The value creation process at the organisational level includes all actions that offer a higher degree of innovation and relevant advantages than what is currently available to the targeted end-user who shows a willingness to pay for this novel result of the actions taken (Lepak et al., 2007). Kang et al. (2007) indicate that an organisation's ability to yield new and qualitative end-user experience is crucial to its long-term success. This success relies on the organisation's ability to develop and utilise its employees' knowledge, which forms the foundation for key innovations that create value for relevant end-users and competitive advantage for the organisation.

Value creation at the individual and organisational level is more controlled and deliberate, compared to the institutional level where organisations or entities can engage deliberately or unintentionally in creating value for both themselves and society at large (Lepak et al., 2007). Just as an organisation functions within a value chain, it also functions within a value network that consists of the different stakeholders in its operations that have a role to play in the creation, evaluation, allocation and realisation of the value being created (Peppard \& Rylander, 2006). Creating value at an individual level mainly requires innovation within the role and performance within the work role, at the organisational level it requires creativity and the promulgation of knowledge and at the institutional level it requires innovation and a vetted value network and value chain for co-creation (Lepak et al., 2007).

Business models, relationship management and value management frameworks are most prevalent frameworks that have been proposed as guidelines through which an organisation can direct its activities and decisions in serving its stakeholders. The overarching goal of a business model for an organisation is to serve a perceived expectation to ultimately create value for the organisation and its associates. Originally, the frameworks proposed an unidirectional flow from the organisation to the customers. Freudenreich et al. (2019) expanded on this by applying the stakeholder theory to provide a framework to explain how a multi-directional flow is indeed realistic, demonstrated in Figure 2.

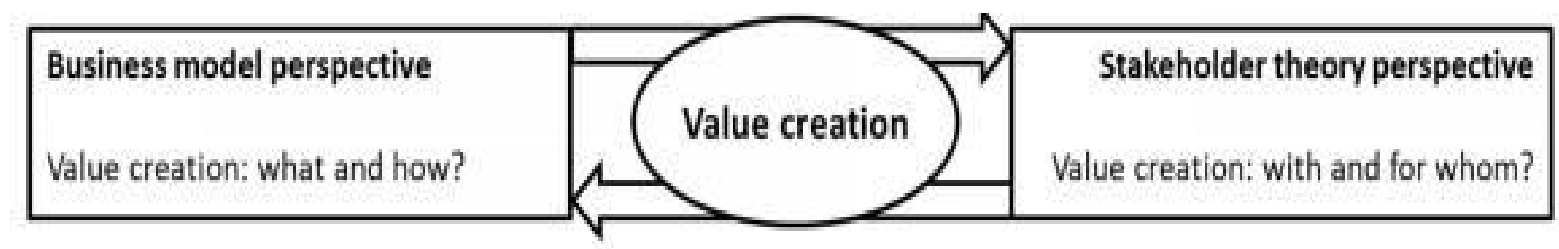

Figure 2 - Value creation through the Business model and Stakeholder theory perspective

Source: Freudenreich et al. (2019) 
The flowchart demonstrates that literature on value creation incorporates both the business model perspective and the stakeholder theory perspective (as a complementary perspective) to showcase the concept of value creation. Freudenreich et al. (2019) further describes relationship management as a second framework that can be utilised as guidelines towards value creation for stakeholders. Figure 3 summarises the stakeholders, what amounts to value in each relationship and how it is co-created with each stakeholder.

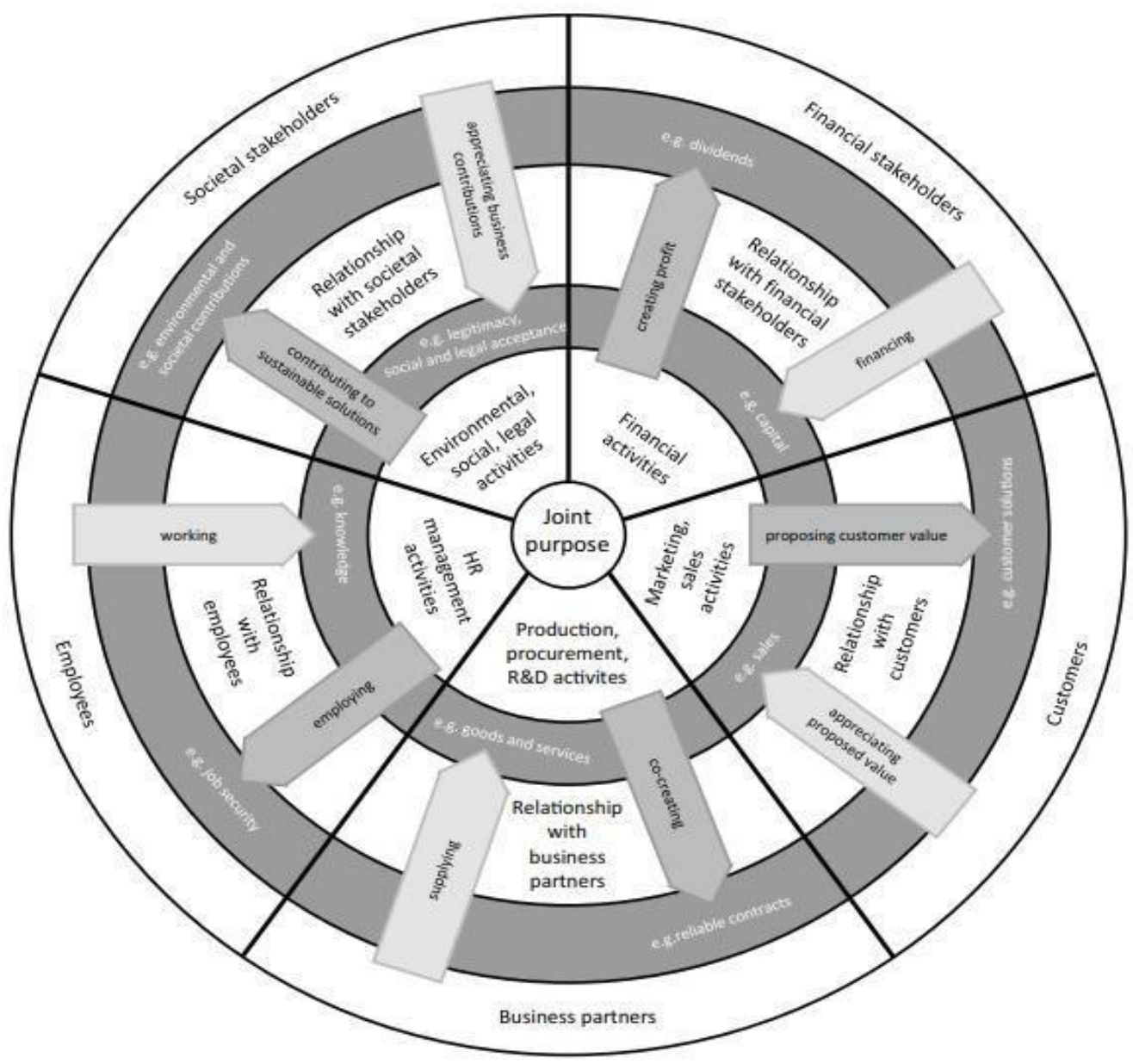

Figure 3 - Process of stakeholder value creation

Source: Freudenreich et al. (2019)

Figure 3 shows that stakeholders can be categorised into five broad categories, which can further be demarcated into a number of specific stakeholders and value can be created for each of them.

The Resource Based View (RBV) theory was further developed by Freudenreich et al., (2019) to recognise value creation and capture it and confirmed the finding that value creation is not 
a uniform process, but a collaborative attempt between stakeholders who are primarily responsible to create and negotiate the value that is being pursued around the same shared value proposition. The business model can be used alongside the RBV by capturing and communicating the value proposition, which then forms the axis for the shared value propositions around which the value is then pursued in a coordinated attempt between all the stakeholders within the value creation process.

The Value Based Management (VBM) framework is another predominant framework. VBM is a systematic strategic management process aimed at aligning the organisations' strategy, systems, procedures, decision-making and its measurement of the organisational performance with value creation. It puts value creation at the centre of the organisation's strategy and has been proved to lead to increased organisational performance (Burkert \& Lueg, 2013; Firk et al., 2016). These advances in the research on management accounting ideally equip the management accountant with new tools, methods and frameworks for their role of providing insight and meaningful information on how an organisation creates value through its interactions with its stakeholders.

\section{Stakeholders and value creation}

In an attempt to make sense of what guides the decision making of stakeholders in pursuing value created by an organisation or engaging in a value creation process, the utility function was proposed. The utility function aims to determine what the preferences of the stakeholder's are for different intangible and tangible outcomes from the actions taken by the organisation (Harrison et al., 2010). Sen (2004) identified a few problems with the utility function and its apparent shortcomings. He argued that representing stakeholder welfare instead of stakeholder utility requires a more valuation-oriented philosophy. Sen (2004) articulated the main shortcomings by explaining that since the argument that utility seems to be the only root of value that depends on linking usefulness with welfare, well-being may not be the only valuable thing in the motivation for the decision making of stakeholders and the utility does not truly represent stakeholder welfare.

Sen (2004) then proposed a novel theory on stakeholder welfare called the capability approach, which was based on the notion of stakeholder capability. By shifting the emphasis from utility to capability, this new framework makes provision for the apparent shortcomings experienced in the utility function. The capability approach is based on valuation activity, which builds on the principle of agency and autonomy, and is recognised as having the propensity to devise objectives and values and to choose between different scenarios. The collaborative approach in which the stakeholders decide themselves on what is important to them is an appropriate measure for identifying the capabilities of the stakeholders in each organisation's unique context (Garriga, 2014).

Organisations around the world are pressured in the sense that their actions have to be more transparent and their decisions need to be more sensitive and accountable to the stakeholders whom they are serving and representing (Ovunda, 2015). These changes in the global business landscape, has led to the role of the management accountant to change as well. The speed of technological advances challenges the very core of the finance function. Management accountants now have to fulfil multiple demands and have a diverse cross-section of business skill sets to stay relevant in order to effectively advise organisations in this high-paced business environment. 


\section{Management accounting and value creation}

The role of management accountants has shifted from a reactive functional approach (backwards-looking and analysing in nature), towards a proactive approach (more forwardlooking and decision-making in nature) that has a professional role within the organisation (Kamal, 2015). Intangible values such as reputation, expertise and brand are increasingly becoming the most critical components of an organisation's long-term success (Baldvinsdottir et al., 2010). In management accounting, a key issue is "managing" the different expectations of the stakeholders the organisation serves. Every decision an organisation makes in servicing an expectation has a cost to it (Shank et al., 1993; Mohamed \& Jones, 2014). This is why the role of the management accountant is so crucial in this process and why the role has evolved from an internally focused role to more of a "business partner" role, with the ability and skill to function in a position that understands the entire organisation's cost structure to do strategic cost management and understands the organisation's strategic position relative to the market (McNair et al., 2001; Brands \& Holtzblatt, 2015).

Most frameworks available to management accountants in managing the relationship between value and cost fail to capture the complexity of this relationship. To resolve this drawback, McNair et al. (2001) proposed a framework called Value Creation Management (VCM), which allows management accountants to link the relationship between cost and value in a way that allows them to assess multiple choices for the investment of resources in an organisation and to maximise the potential gains and reinforce its competitive market position.

Therefore, the role of the management accountant has become a vector of sorts, walking the line between the traditional "paper" role of cost accounting, drafting budgets, implementing controls and capturing value to make sure the numbers add up on paper and balance at the end of the day. There is also the added responsibility of managing the "people" component, both in a managerial capacity of managing the employees and stakeholder's interests, and as a resource for the organisation in understanding the role people have in either adding value or being the source of value in themselves. In bringing these elements together, the management accountant has to possess the skill to provide insight into how people create value and how that value can be captured through measuring their performance to be communicated on paper to those making the decisions for the organisation, or who expect results from the organisation. This new form that the role of the management accountant has assumed links these elements together and ultimately plays a crucial role in enabling the organisation to pursue value creation for its stakeholders (Cinquini \& Tenucci, 2010; Mohamed \& Jones, 2014; Malmi, 2016).

\section{Managing the measurements}

Performance measures within the management accountant's conventional role of implementing financial indicators to measure how a certain activity or function is performing has seldom been challenged. However, the increasing pressure of companies to communicate to all its stakeholders how the organisation is doing business, outside of only the financial information, has posed a much greater challenge in presenting performance measures for non-financial organisational activities (Ittner \& Larcker, 2001; Mohamed \& Jones, 2014).

The dawn of the 21 st century saw the conventional empirical research in management accounting on themes such as budgeting and financial control techniques, make way for studies with advanced theories and methods with the likes of activity-based costing, balanced 
scorecard, strategic accounting and performance measurements of added value (Ittner \& Larcker, 2001). A tool such as VBM provides a conceptual framework whereby management accountants may identify, introduce and apply value-creating tactics within the organisation, and which provides the ability to track and coordinate management activities.

VBM's distinguishing trait is value-based indicators. These value-based indicators offer an effective way of designing new organisation strategies, assigning the required resources and expertise for implementing the strategy and setting measurable targets in the alignment of the organisation's goals by creating value for the organisation and its stakeholders (Omran et al., 2002). The dilemma of having multiple stakeholders with conflicting interests often complicates the concept of value creation and further highlights the necessity of value capture and performance measurement (Lepak et al., 2007). This is where the organisation really requires the management accountant, as an aide-de-camp of sorts, to translate value creation from theory to practice.

Value capture can only happen if the value creation process along with the contribution of each role-player is understood. If a gain was realised through the co-creation with another stakeholder, that gain most likely needs to be shared with the other party who helped create the value. If a gain was realised within an organisation, because of the collaboration of two or more departments, even though the organisation realises the entire gain, there is the internal competition of who is credited what percentage of the gain realised (Firk et al., 2016, Schutte \& Lovecchio, 2017).

Ulaga (2003) uses nine dimensions to measure value between manufacturer and supplier relationships, based on their research into the theory of value measurement. Ulaga (2003) did this by identifying relational value drivers that can indicate the performance of the specific relationship. The framework demonstrates that each of the relationships will have different value drivers and it is up to the organisation to identify which stakeholders are the most important and to find a solution on how to manage conflicting stakeholder expectations.

Research by Argandoña (2011) aimed to understand the incentives that an individual looks for as the result for undertaking a certain action. The findings identified five main types of value an individual hopes to realise for themselves that preemptively sheds light on what these reasons may be for the management accountant to engage in the value creation process. These are economic value, intangible value, psychological value, intrinsic value and transcendent value. These incentives for engaging in certain activities and specifically investing in the value creation process, both formally as required by the organisation and measured through metrics such as KPI's and informally through the behaviour of the individual within their personal capacity within this process, are important considerations in understanding the how a management accountant views the value creation process within the organisation. If an organisation pursues several types of value it provides the organisation with the ability to create both economic and non-economic value in a more sustained way by entering into strategic relationships with its stakeholders that may be direct or indirect, so all the stakeholders benefit from the value being created. 


\section{Problem Statement}

Most of the company's value is found in the intangible elements of its business model, such as the levels of trust, innovation, corporate governance and culture that are increasingly harder to measure. No consensus on what stakeholder value should be measured, how it should be measured, or the action that should be taken to arrive at metrics that matter (Lepak et al., 2007). Without this challenge being solved, the lack of verifiable metrics that stakeholders can trust, will lead to companies being unable to communicate how they are creating value (Freudenreich et al., 2019).

This challenge is not only in the case of the company as a whole, but is further reflected in the role of the management accountant. A management accountant has a point of tension between the "measurement" and "management" role (Ittner \& Larcker, 2001; Järvenpää, 2007; Malmi, 2016). In the measurement role, the performance of the management accountant can be quantifiable in the form of the numeric data relating to the costs of the internal business processes. In the management role, which includes the "creation of value" role, it is much harder to quantify, as the value being added is completely subjective and unique to the specific role and the specific organisation. Management accountants can successfully measure the value of money in their cost control function, but it remains a challenge on how they perceive the adding or creating of value in their respective roles and if their own perceived performance in their creation of value is shared by the managers of that organisation. The perceptions held by management accountants about their own performance, how they create value and if they can measure it therefore deserves exploration.

\section{METHODOLOGY}

\section{Theoretical framework and philosophical orientation}

This research was conducted using the stakeholder theory (Jensen, 2010), and made a relativistic ontological assumption about the reality of the experiences and perception of the management accountant, which allowed the researcher to gain insight into the specific context of the individual (Killam, 2013). And from an epistemological approach (Killam, 2013; Blair, 2016), the researcher intended to interact with the participants of the research by following an emic approach to be able to draw conclusions from the knowledge about the experiences of the participants discovered through the interaction with them. An interpretivist approach was followed, which called for a qualitative approach to gathering the type of data that is required for the purposes of drawing meaningful conclusions from the perceptions and experiences of the management accountants who are participants in the research (Lin, 1998).

\section{Research design}

This research adopted an overall qualitative approach in terms of data collection, data analysis and results interpretation, since this study attempted to gain an understanding of the viewpoints of management accountants in relation to the phenomena researched in this study. This study required the collection of qualitative data as the phenomena does not allow for concise measurements, but rather for observations through the interaction with the participants from which there were meaningful conclusions induced about the perceptions and experiences. It is also exploratory in nature (Dudovskiy, 2016). 


\section{Research (data collection) instrument}

In addition to a literature review on existing research on value and value creation in organisations, along with the role of the management accountants pertaining to value creation, this study used a qualitative questionnaire, specifically designed for this study, to gather the qualitative empirical data to provide insight into the perspective and experience of the management accountant in navigating the ambiguities within their role of what is prescribed in theory and what is expected in practice, and how they then measure their own performance or contribution to the value creation process in adding, creating or capturing value for the organisation and its stakeholders.

\section{Population and sampling strategy}

Qualitative sampling concentrates on small sample sizes in order to extract rich information, which provides a good understanding of the phenomena being studied (O'reilly \& Parker, 2013). A sample size of 30 participants were concluded for this study, and this sample size sufficiency is supported by other comparable qualitative research done in accounting through studies such as those of Kamal et al. (2015) and Conway et al. (2015) to support the level of "saturation" for this study. Furthermore, the sample was selected using the snowball sampling strategy whereby the recruiting of participants was done through the help of other participants to ensure the sample was sufficiently representative to provide adequate information to draw meaningful conclusions about the population in question.

\section{Ethical considerations}

Participants took part in this study on a voluntary basis and none of the participants were incentivised for their participation. A voluntary participation declaration letter of consent was distributed to all participants to sign. The questionnaire was anonymous and did not request the participants to include their names. The data collected and results obtained were reported for the collective group, and no specific reference was made to a specific participant. Ethical clearance to conduct this study was also obtained from the North-West University Economic and Management Sciences Research Ethics Committee.

\section{RESULTS AND DISCUSSIONS}

\section{Demographics and current context of the management accountant}

The geographical representation of the participants was predominantly from the Gauteng Province (53\%), followed by both the Western Cape and the North-West with 20\%, and finally both the Free State and Namibia with $3 \%$ of the participants. The gender profile consisted of $73 \%$ males and $27 \%$ females, with the average age of the respondents at 24 years and 10 months.

Figure 4 shows that the most participants that took part in this study are currently employed within either a management accountant or financial accountant role ( $20 \%$ respectively). 


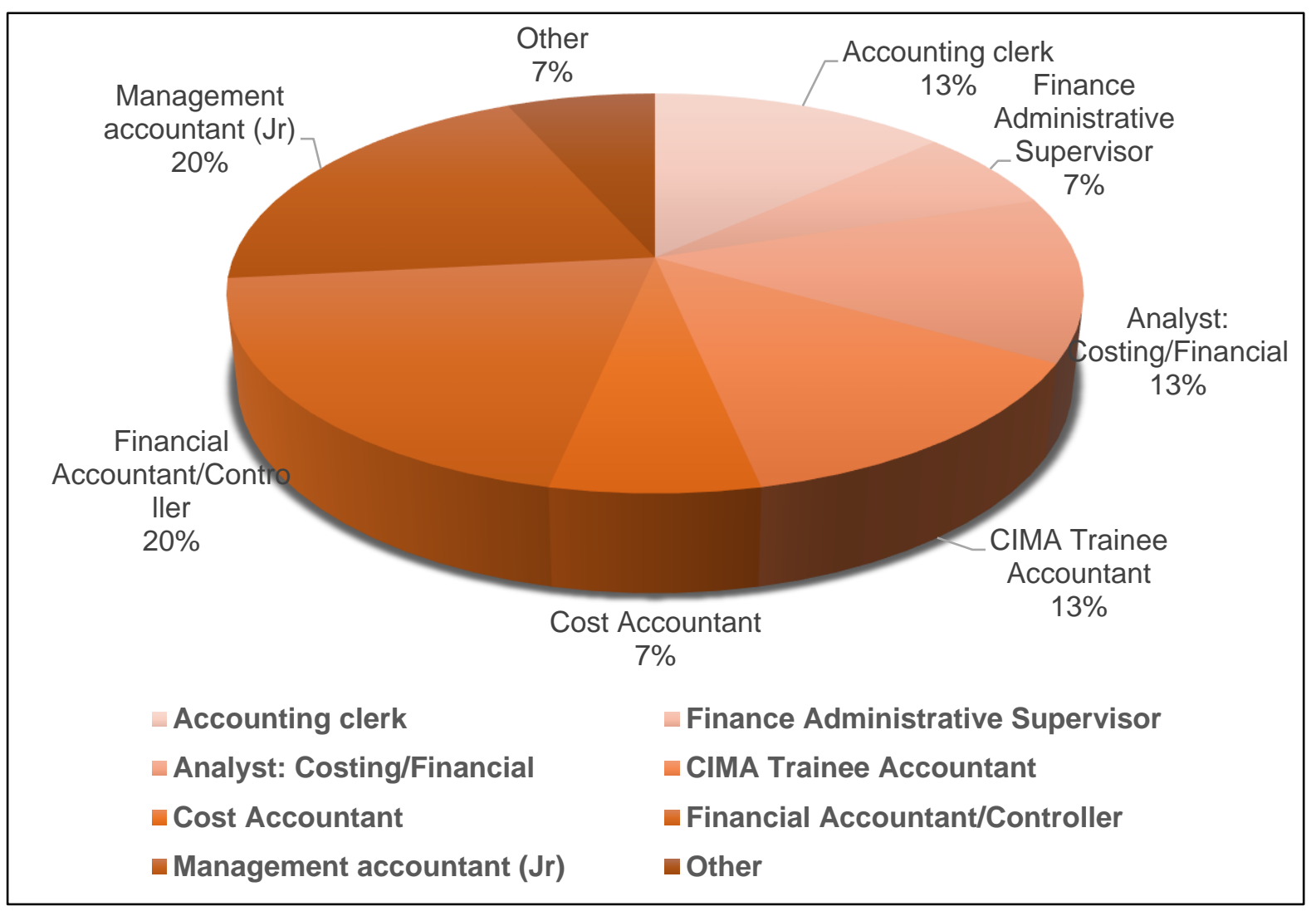

Figure 4 - Position held in organisation

In terms of the academic background, $96.67 \%$ of all participants hold an honours degree in management accountancy and $66.67 \%$ have successfully passed their CIMA exams. Majority of the participants hold entry level or junior positions, which makes sense, since all of the participants had graduated in the past five years. The three main industries participants are employed in are Banking/Consulting (30\%), Accounting (23\%), and Construction/Property management (17\%). The remaining 30\% of the industries are Mining (13\%), Other (10\%) made up of Education, Logistics and Oil/Fuel, and lastly, Manufacturing/Agriculture (7\%).

The participants only function on two levels of the possible three within the organisation, being $73 \%$ on the operational level and $27 \%$ on the managerial level. And their duties include, but not limited to, doing tax calculations and tax preparations, reconciliations, preparing financial statements, developing and maintaining cost models, variance analysis, budgets and forecasts, operational performance report compilations, management report compilations, internal auditing, financial model preparation, data analysis, automation of financial report processes, cloud-based accounting systems set-up and client portfolio management.

\section{Value creation results and discussions}

The purpose of this section is to gain understanding about how the concept of value creation is understood and applied by the respondents by having the questions focus on: 1) the theoretical introduction to the concept of value creation; 2) the hypothetical understanding of creating 
value in the role of a management accountant; 3) if the respondent believes they are currently creating value for the organisation within their role; 4) how they believe they are creating value within their role; 5) the different types of value being created by the management accountants in their role.

All the participants confirmed they were familiar with the concept of value creation, and that they were formally exposed to the concept for the first time during their tertiary studies. The participants were probed as to what it means to create value in an organisation within their roles as management accountants and most of the answers approached the concept of value creation through an economic lens. This is in line with the fact that the majority of the participants function on an operational level within the organisation. Due to the technical skills that are emphasised on this level, the expectation is that due to their current expectations in the workplace, this would be the interpretation and potential application of value creation.

There was also consensus among most of the answers that information management is a key element for the ability to create value, as the quality of the decision-making ability is entirely reliant on the quality of the information. One of the participants' answers captured the key problem identified for this study; the fact that even though value creation is definable from a theoretical starting point, it does not translate straightforwardly to the reality of the working place and therefore it may even be deemed "too idealistic" or "too unrealistic."

In a follow-up question, participants were probed on whether they believe that they are creating value in their employment organisation. Eighty-three percent of participants are of the view that they are creating value in their employment organisation, whereas only $17 \%$ believe that they do not or are unsure whether they are creating value. Another follow-up question asked the respondents to specify how exactly they are currently creating value in their employment organisation. Participants who are of the view that they create value, provided the following notable reasons:

- They are sharing personal life experiences and lessons with fellow employees in an attempt to prompt them to create value in the organisation;

- Managing and saving cost for the organisation;

- Reporting financial and other information accurately and in a timeous manner;

- Incorporating technological software such as Microsoft Excel, Database and SQL to improve efficiency of reporting and reducing time spent on tasks;

- Contributing towards positive morale to the team and innovating processes;

- $\quad$ Performing tasks that assist the organisation in understanding itself better by providing important information on how everything in the organisation functions.

Those participants who do not feel that they are adding value or who are unsure cite the reason as being that the role they are currently in is prohibiting them from making a real impact and to follow a set guide of rules from which they are not allowed to deviate from, hence prohibiting creativity, innovation and transformation away from the norm. 
These answers revealed more about the internal perspective of the respondents. It alluded to both their attitude and their understanding about value creation. Those who defined/understood value creation in purely economic/numeric/quantitative terms and their contribution in that sense had a harder time explaining how they create value than respondents who explained it in relational or qualitative terms.

When participants were probed to describe the different types of value they perceive themselves to create within their organisations, the following information was revealed:

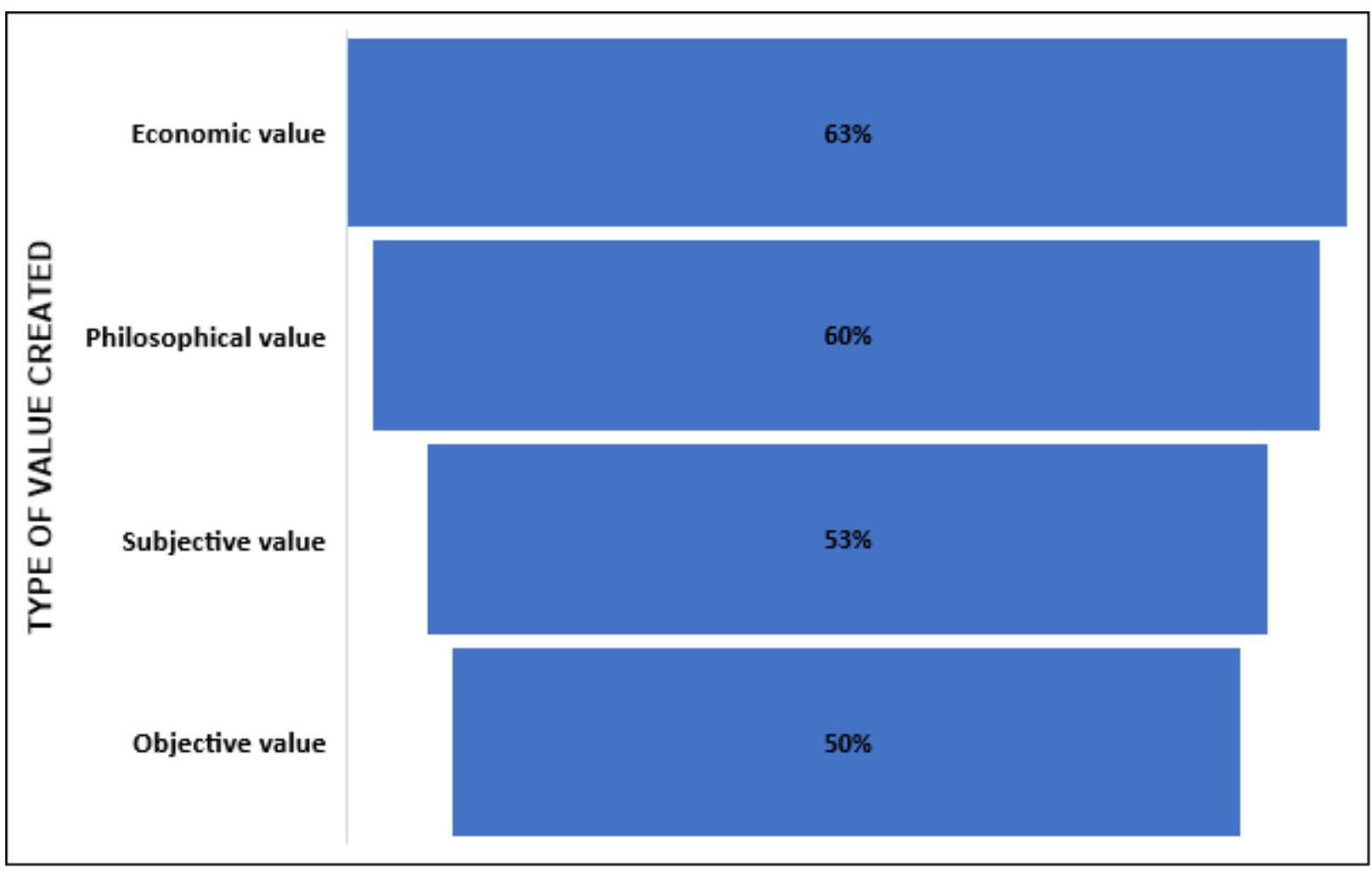

Figure 5 - different types of value currently created within their role

Sixty three percent of participants believe that they are creating economic value, whereas only $50 \%$ believe they create objective value.

\section{Stakeholder results and discussions}

Almost all of the participants, with the exception of one, believed they were creating value for the stakeholders of the organisation, whether directly or indirectly. The customers, shareholders and other employees were the favourite recipients of the value the management accountants believed they were creating. The local community and the suppliers of the organisation were solidly in last place. One of the participants noted that they feel that the notion to add value to all stakeholders is "unfair", because all stakeholders are not equal, and creating value for all stakeholders is an impossible task to achieve. In terms of their organisational stakeholder value creation model, a stakeholder hierarchy is adopted. And once 
the organisation knows which stakeholders are most important to them, value is created and measured for those stakeholders only.

It is highly unlikely that an organisation would ever publicly admit to it, it is worth asking if it is realistic for an organisation to create value for all of its stakeholders simultaneously. Is a "stakeholder hierarchy", as the participant proposes, a viable option; perhaps in prioritising the expectations and the allocation of resources. The submission is definitely expanding on the stakeholder literature explored in this study, especially when looking at the model of Freudenreich et al. (2019) and identifying the value contribution of each relationship and then prioritising conflicting resources from the highest value contribution. This submission provides invaluable insight to the honest reality that certain elements of value creation could potentially be too idealistic in practice when it comes to attempting to realise that which is recommended on paper.

Furthermore, it is worth noting that the reason for the disparity among which stakeholders interests the participants believe they are serving, is due to the direct vs the indirect effect their contribution has on those stakeholders. It is possible for a majority of the participants to directly contribute to the shareholder, customers and their colleagues, but their interaction and contribution towards the suppliers and local community of the organisation is indirect and therefore, even though the organisation can directly contribute value to these two stakeholder groups, it is much harder to attribute that contribution to the individual. This supports the findings identified through the research of Firk et al. (2016) regarding the issues relating to the attribution of the gain or value being created.

All the participants recognised that the organisation has to have its stakeholders' best interests at heart, and that that is a major part of the value creation process; however, the respondent's personal contribution in that value creation process was more "traceable" for some stakeholders than others.

\section{Performance and value capture results and discussions}

The ability of the management accountant to create value appears to be easier than the ability to capture and then convey or communicate that value. In a role and on a level within the organisation that requires all contributions to be measured it is clearly an area that requires further examination, as not all the respondents were able to confirm that the value they believe they are creating can be measured. Only $63 \%$ confirmed that the value they create could be readily measurable. This provides a glaring dilemma, for what the incentive is for the individual in creating value. It also means that if value creation activities are to be pursued, the measurable types of value, such as objective and economic value, may receive preference above those types that are not readily measurable.

Motivation is another major consideration, as identified by Argandoña (2011), in assessing the willingness and likeliness for an individual to pursue value creation. Almost all the participants confirmed they could potentially produce better results in their ability to create value if additional arrangements, aside from their normal remuneration, were available as incentives for them to pursue those activities. Most of the participants confirmed their organisations also introduced them to value creation and a large majority are all still furthering their professional development through formal academic training to be able to make a more meaningful contribution. These are both necessary variables in creating a value creation culture within an 
organisation, where the individual and the organisation communicate their commitment to value creation. The organisation can communicate its commitment through explicitly communicating it and encouraging or rewarding this behaviour and the individual can do this through furthering their professional development so that their contribution can be more meaningful.

Most of the participants who confirmed the value they create can be measured, were creating economic value, but those who created more intangible or subjective types of value, confirmed that either their value was not measurable, or that it could not be attributed to an individual. Another interesting submission from the participants was how to illustrate the value creation process: "Any industry's value chain is like a web, rather than a chain, meaning every stakeholder's actions directly/indirectly influences another's. To isolate an individual part of this web is very difficult, nigh impossible I'd say. Because one can't isolate a part of the web, it's difficult to accurately measure any person's portion."

The popular theory of the value chain, as first proposed by Porter (1985), explains the value creation process as a value-chain, but perhaps it is worth looking at the value creation process as a multi-dimensional web, as proposed by Freudenreich et al. (2019), rather than a unilateral chain.

\section{CONCLUSIONS AND RECOMMENDATIONS}

The primary objective of this study was to understand the management accountant's perception of their performance, and how they created value in their role, and for the organisation. This research study has succeeded in that purpose through the insight gained through the existing literature, along with the analysis of the questionnaire responses. The research shows that a cavity exists between the management accountant's ability to create value in their role, and the organisation's ability to measure the value created. The feedback suggests that value creation in its current form is overly reliant on the subjectivity of the creator, but value realisation or the capture thereof, is completely reliant on the tools available to the value capturer to confirm or disprove the value created. With stakeholder expectations in the 21 st century demanding ethical behaviour and good corporate governance, along with sustainable business practices, the management accountant continues to play a key strategic role in the organisation's ability to create, capture and communicate the value that the organisation is pursuing. This study has therefore illustrated that the ability to create value is not dependent on only the individual and their contribution; it has to be in tandem with the organisation, who on their part have to create a conducive environment as an incentive for the employees to create value.

Limitations of this study are that the average level of experience of the participant may have also been a limitation to the study and the research findings are based on the perceptions of the participative management accountants, and not their managers or any other stakeholders.

Further research opportunities include repeating the study on management accountants who have been in the workplace for longer and who function on mainly the strategic level in their organisations; as well looking into the possible development of tools, models or frameworks to assist management accountants in the measuring or capturing of value that is of a more subjective nature, so that it would be easier to implement and drive value creation practices in the workplace. 


\section{REFERENCES}

Argandoña, A. 2011. Stakeholder theory and value creation. Barcelona: IESE Business School Working Paper No. 992.

Audi, R. 2003. Intrinsic value and reasons for action. The Southern Journal of Philosophy, 41(s):30-56.

Baldvinsdottir, G., Mitchell, F. \& Nørreklit, H. 2010. Issues in the relationship between theory and practice in management accounting. Management Accounting Research, 21(2):79-82.

Blair, L. 2016. Writing a graduate thesis or dissertation. Canada: Sense publishers.

Bowman, C. \& Ambrosini, V. 2007. Identifying valuable resources. European Management Journal, 25(4):320-329.

Brands, K. \& Holtzblatt, M. 2015. Business Analytics: Transforming the Role of Management Accountants. Management Accounting Quarterly, 16(3).

Burkert, M. \& Lueg, R. 2013. Differences in the sophistication of Value-based ManagementThe role of top executives. Management Accounting Research, 24(1):3-22.

Carney, M. 2014. Inclusive capitalism. In speech at the Conference on Inclusive Capitalism, 27:83-110.

CGMA. 2012. A decade of change - the evolution of value creation. https://www.cgma.org/content/dam/cgma/resources/reports/downloadabledocuments/le dgers-ch1-decadeofchange.pdf Date of access: 18 Feb. 2019.

Cinquini, L. \& Tenucci, A. 2010. Strategic management accounting and business strategy: a loose coupling? Journal of Accounting \& Organizational Change, 6(2):228-259.

Conway, S.L., O'Keefe, P.A. \& Hrasky, S.L. 2015. Legitimacy, accountability and impression management in NGOs: The Indian Ocean Tsunami. Accounting, Auditing Accountability Journal, 28(7):1075-1098.

Dudovskiy, J. 2016. The ultimate guide to writing a dissertation in business studies: a stepby-step assistance. Pittsburgh, USA.

Firk, S., Schrapp, S. \& Wolff, M. 2016. Drivers of value creation-The role of value-based management and underlying institutions. Management Accounting Research, 33:42-60.

Freeman, R.E. 2010. Strategic management: A stakeholder approach. Cambridge university press.

Freudenreich, B., Lüdeke-Freund, F. \& Schaltegger, S. 2019. A stakeholder theory perspective on business models: Value creation for sustainability. Journal of Business Ethics, 166(1):16.

Garriga, E. 2014. Beyond stakeholder utility function: Stakeholder capability in the value creation process. Journal of Business Ethics, 120(4):489-507.

Hansell, G. 2012. Value Patterns: The Concept. https://www.bcg.com/publications/2012/value-creation-strategy-corporate-strategyportfolio-management-value-patterns.aspx Date of access: 18 Feb. 2019.

Harrison, J.S., Bosse, D.A. \& Phillips, R.A. 2010. Managing for stakeholders, stakeholder utility functions, and competitive advantage. Strategic Management Journal, 31(1):5874.

Hart, S.L. \& Milstein, M.B. 2003. Creating sustainable value. Academy of Management Perspectives, 17(2):56-67.

Hofmann, E. 2003. The flow of financial resources in the supply chain: creating shareholder value through collaborative cash flow management. Wiesbaden, pp. 94-117. 
Ittner, C.D. \& Larcker, D.F. 2001. Assessing empirical research in managerial accounting: a value-based management perspective. Journal of Accounting Economics, 32(1-3):349410.

Järvenpää, M. 2007. Making business partners: a case study on how management accounting culture was changed. European Accounting Review, 16(1):99-142.

Jensen, M.C. 2010. Value maximization, stakeholder theory, and the corporate objective function. Journal of Applied Corporate Finance, 22(1):32-42.

Kamal, O., Brown, D., Sivabalan, P. \& Sundin, H. 2015. Accounting information and shifting stakeholder salience: an industry level approach. Qualitative Research in Accounting, 12(2):172-200.

Kamal, S. 2015. Historical evolution of management accounting. The Cost Management, 43(4):12-19.

Kammel, B. 2019. People Trust Their Boss a Lot More Than the Government or the Media. Bloomberg. https://www.bloomberg.com/news/articles/2019-01-20/employees-useworkplace-as-source-of-trust-as-pessimism-persists Date of access: 18 Feb. 2019.

Kang, S.C., Morris, S.S. \& Snell, S.A. 2007. Relational archetypes, organizational learning, and value creation: Extending the human resource architecture. Academy of Management Review, 32(1):236-256.

Killam, L. 2013. Research terminology simplified: Paradigms, axiology, ontology, epistemology and methodology. Laura Killam.

Laszlo, C. 2008. Sustainable value: How the world's leading companies are doing well by doing good. Stanford University Press.

Lepak, D.P., Smith, K.G. \& Taylor, M.S. 2007. Value creation and value capture: A multilevel perspective. Academy of Management Review, 32(1):180-194.

Lin, A.C. 1998. Bridging positivist and interpretivist approaches to qualitative methods. Policy Studies Journal, 26(1):162-180.

Lockhart, J.C. \& Taitoko, M. 2005. An examination of shareholder-stakeholder governance tension: A case study of the collapses of Ansett Holdings and Air New Zealand. Advances in Public Interest Accounting, 11(1):223-246.

Lyibildiren, M. 2017. Effects of Management Accounting Practices and Performance Measurement on the Perception of Business Performance: Field Study on Organized Industrial Zone of Konya. Journal of Knowledge Management, Economics and Information Technology, 7(4):14.

Malmi, T. 2016. Managerialist studies in management accounting: 1990-2014. Management Accounting Research, 100(31):31-44.

McNair, C.J., Polutnik, L. \& Silvi, R. 2001. Cost management and value creation: the missing link. European Accounting Review, 10(1):33-50.

Mohamed, A.A. \& Jones, T. 2014. Relationship between strategic management accounting techniques and profitability-a proposed model. Measuring Business Excellence, 18(3):1-22.

O'reilly, M. \& Parker, N. 2013. 'Unsatisfactory Saturation': a critical exploration of the notion of saturated sample sizes in qualitative research. Qualitative Research, 13(2):190-197.

Omran, M., Atrill, P. \& Pointon, J. 2002. Shareholders versus stakeholders: corporate mission statements and investor returns. Business Ethics: A European Review, 11(4):318-326.

Ovunda, A.S. 2015. The development of cost and management accounting: A historical perspective. European Journal of Humanities Social Sciences, 34(1). 
Peppard, J. \& Rylander, A. 2006. From value chain to value network: Insights for mobile operators. European Management Journal, 24(2-3):128-141.

Pitelis, C.N. 2009. The co-evolution of organizational value capture, value creation and sustainable advantage. Organization Studies, 30(10):1115-1139.

Porter, M.E. \& Kramer, M.R. 1985. Competitive advantage: creating and sustaining superior performance. Insights, 1:3-52.

Porter, M.E., Hills, G., Pfitzer, M., Patscheke, S. \& Hawkins, E. 2012. Measuring shared value: How to unlock value by linking business and social results. Harvard Business Review, 84(12):78-92.

Robertson, P.J. \& Tang, S. 1995. The Role of Commitment in Collective Action: Comparing the Organizational Behavior and Rational Choice Perspectives. Public Administration Review, 55(1): 67-80.

Schilizzi, S. 2000. The economics of ethical behaviour and environmental management. 44th Annual Conference of the AARES, January 23-25, 2000.

Schutte, D. \& Lovecchio, B. 2017. An Evaluation of the Competence Requirements of South African Accountants Practising in the SME Environment. Journal of Social Sciences, 53(2): 61-72.

Sen, A. 2004. Capabilities, lists, and public reason: continuing the conversation. Feminist Economics, 10(3):77-80.

Shank, J.H., Govindarajan, V. \& Govindarajan, S. 1993. Strategic cost management: The new tool for competitive advantage. Simon and Schuster.

Ulaga, W. 2003. Capturing value creation in business relationships: A customer perspective. Industrial Marketing Management, 32(8):677-693.

Zwikael, O. \& Smyrk, J. 2011. Project management for the creation of organisational value. Springer. 